\title{
Defects in secretion, aggregation, and thrombus formation in platelets from mice lacking Akt2
}

\author{
Donna Woulfe, ${ }^{1}$ Hong Jiang, ${ }^{1}$ Alicia Morgans, ${ }^{1}$ Robert Monks, ${ }^{2}$ Morris Birnbaum, ${ }^{2}$ \\ and Lawrence F. Brass ${ }^{1,3,4}$ \\ ${ }^{1}$ Department of Medicine, \\ ${ }^{2}$ The Howard Hughes Medical Institute, \\ ${ }^{3}$ Department of Pharmacology, and \\ ${ }^{4}$ Center for Experimental Therapeutics, University of Pennsylvania, Philadelphia, Pennsylvania, USA
}

\begin{abstract}
Prior studies have shown that PI3Ks play a necessary but incompletely defined role in platelet activation. One potential effector for PI3K is the serine/threonine kinase, Akt, whose contribution to platelet activation was explored here. Two isoforms of Akt were detected in mouse platelets, with expression of Akt2 being greater than Akt1. Deletion of the gene encoding Akt2 impaired platelet aggregation, fibrinogen binding, and granule secretion, especially in response to low concentrations of agonists that activate the $\mathrm{G}_{\mathrm{q}}$-coupled receptors for thrombin and thromboxane $A_{2}$. Loss of Akt2 also impaired arterial thrombus formation and stability in vivo, despite having little effect on platelet responses to collagen and ADP. In contrast, reducing Akt1 expression had no effect except when Akt2 was also deleted. Activation of Akt by thrombin was abolished by deletion of $\mathrm{G} \alpha_{\mathrm{q}}$ but was relatively unaffected by deletion of $\mathrm{G \alpha}_{\mathrm{i} 2}$, which abolished Akt activation by ADP. From these results we conclude that Akt2 is a necessary component of PI3K-dependent signaling downstream of $\mathrm{G}_{\mathrm{q}}$-coupled receptors, promoting thrombus growth and stability in part by supporting secretion. The contribution of Akt1 is less evident except in the setting in which Akt2 is absent.
\end{abstract}

J. Clin. Invest. 113:441-450 (2004). doi:10.1172/JCI200420267.

\section{Introduction}

Platelet activation is important for mediating hemostasis, but also contributes to thrombosis in the arterial circulation, the primary cause of heart attacks and strokes. Platelets first become activated at sites of vascular injury when they encounter matrix proteins exposed by injury to the vessel wall. Platelets arrest on the exposed subendothelial surface, become activated, and secrete or generate soluble mediators, such as ADP, thromboxane $\mathrm{A}_{2}$, and thrombin. All of these soluble agonists recruit circulating platelets to the growing platelet plug by activating $G$ protein-coupled receptors on the platelet surface. Exposure of platelets to any of the above soluble agonists, for example, results in activation of the heterotrimeric $G$ protein, $G_{q}$, and leads to release of calcium from intracellular stores. Although an increase in the intracellular calcium concentration is both necessary and sufficient to initiate platelet aggregation, addi-

Received for publication October 9, 2003, and accepted in revised form December 2, 2003

Address correspondence to: Donna Woulfe, Thomas Jefferson University, 412 College Building, 1025 Walnut Street, Philadelphia, Pennsylvania 19107-5083, USA.

Phone: (215) 503-5152; Fax: (215) 503-5731;

E-mail: donna.woulfe@jefferson.edu.

Conflict of interest: The authors have declared that no conflict of interest exists.

Nonstandard abbreviations used: phosphatidylinositol 3,4,5-triphosphate ( $\left.\mathrm{PI}[3,4,5] \mathrm{P}_{3}\right) ; \mathrm{PI}(3,4) \mathrm{P}_{2}$ phosphatidylinositol 3,4-diphosphate $\left(\mathrm{PI}[3,4] \mathrm{P}_{2}\right)$; protease-activated receptor 4 (PAR4); glycogen synthase kinase-3 $\beta$ (GSK-3 $\beta$ ); platelet-rich plasma (PRP); 5-hydroxytryptamine or serotonin (5-HT). tional signals are required to enhance platelet aggregation and promote stability of the aggregate. The signaling mechanisms that contribute to platelet plug stability are far from understood, however.

Previous studies have established a unique role for ADP in stabilizing platelet aggregates as they form (1-5). This is particularly evident when platelets are stimulated with low concentrations of thrombin or analogues of thromboxane $\mathrm{A}_{2}$. Under these conditions, secretion of $\mathrm{ADP}$ is required to elicit irreversible aggregation: in the presence of ADP scavengers or inhibitors of the $\mathrm{G}_{\mathrm{i}}$-coupled ADP receptor, P2Y12, platelets aggregate, but the aggregates become unstable and dissociate (1). This type of "reversible" aggregation is also seen in the presence of PI3K inhibitors and when individual PI3K isoforms are knocked out, demonstrating that PI3K plays an important role in platelet activation (1, $5,6)$. PI3Ks are intracellular lipid kinases that phosphorylate phosphoinositides at the D3 position of the inositol ring. Some of the products of PI3K have been detected following activation of platelets with thrombin, thromboxane $\mathrm{A}_{2}$ analogue, and, to a lesser degree, $\operatorname{ADP}(1,7,8)$. Specifically, platelets stimulated with thrombin generate an early wave of $\mathrm{PI}(3,4,5) \mathrm{P}_{3}$ (phosphatidylinositol 3,4,5-triphosphate) and a later, integrin-dependent wave of $\mathrm{PI}(3,4) \mathrm{P}_{2}$ (phosphatidylinositol 3,4-diphosphate), which is also dependent on secreted ADP (9-11). It is generally accepted that these polyphosphoinositides help to trigger cellular processes at least in part by binding to pleckstrin homology domains of effector proteins, thereby translocating 
them to the membrane where they become an active part of signaling complexes $(12,13)$. One such effector protein, the serine/threonine kinase Akt, has been detected in platelets and becomes phosphorylated after platelets are incubated with thrombin, ADP, or thromboxane $A_{2}(5,14,15)$. Therefore, we sought to determine the role of Akt in signaling pathways that lead to platelet aggregation by these agonists.

Genes encoding three isoforms of Akt are present in humans and mice: Akt1, 2, and 3 (also termed protein kinase $B \alpha, \beta$, and $\gamma$ ) (16). The mRNA encoding Akt 1 and Akt2 have been detected by RT-PCR in human platelets (14), but information about the relative levels of expression of these two isoforms is lacking, in part because of a lack of truly isoform-specific Ab's. To understand the role of Akt in platelet activation, we evaluated platelet function and arterial thrombus formation in mice that lacked either Akt1 or Akt2 and compared the results with those obtained with WT mice or (since the double knockout is lethal) mice in which Akt1 expression was reduced in an Akt2-null background. The results show that Akt2 is the dominant Akt isoform in mouse platelets and that loss of Akt2 alone, but not Akt1 alone, impairs platelet activation by thrombin or thromboxane $\mathrm{A}_{2}$ in vitro and impairs thrombus formation in vivo. The results also show that the activation of Akt by thrombin in platelets is mediated by a $\mathrm{G}_{\mathrm{q}}$-dependent and predominantly PI3K-dependent pathway that does not require secreted ADP. Taken together, the results suggest a mechanism in which low amounts of thrombin or thromboxane $\mathrm{A}_{2}$ stimulate Akt phosphorylation when they bind to and activate $\mathrm{G}_{\mathrm{q}}$-coupled receptors. The activation of Akt helps to promote secretion of ADP and other mediators from platelet-dense granules and $\alpha$-granules and enhances fibrinogen binding. This process is not only important for supporting aggregation in vitro, but clearly plays a role in thrombus formation in vivo.

\section{Methods}

Materials. Unless otherwise specified, reagents were obtained from Sigma-Aldrich (St. Louis, Missouri, USA). LY294002 and U46619 were from CalbiochemNovabiochem Corp. (San Diego, California, USA). The PAR4 (protease-activated receptor 4) agonist peptide, AYPGQV, was synthesized by the Protein Chemical Laboratory of the University of Pennsylvania (Philadelphia, Pennsylvania, USA). Thrombin was the generous gift of John Fenton (New York State Department of Health, Albany, New York, USA).

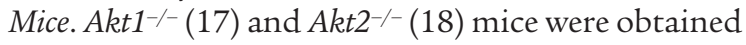
from the lab of Morris Birnbaum (University of Pennsylvania) and have been backcrossed a minimum of five times into a C57BL/ 6 background. All mice were studied at 6-10 weeks of age and were between 18 and $30 \mathrm{~g}$ in weight. C57BL/ 6 mice of the same strain and age were used as control mice. $G \alpha_{i 2}{ }^{-1-}$ mice were obtained from Richard Mortensen (Harvard Medical School,
Boston, Massachusetts, USA) and were in a C57BL/ 6 background. $G \alpha_{q}^{-1-}$ mice were from Stephan Offermanns (Institute of Pharmacology, University of Heidelberg, Heidelberg, Germany) (19) and were maintained in a C57BL/ 6 background. Ethical approval for the animal experimentation detailed in this article was received from the Institutional Animal Care and Use Committee at the University of Pennsylvania.

Akt and glycogen synthase kinase-3 $\beta$ phosphorylation. Blood was collected from the inferior vena cava of anesthetized mice ( $100 \mathrm{mg} / \mathrm{kg}$ pentobarbital) essentially as described (20) using ACD (trisodium citrate, $65 \mathrm{mM}$; citric acid, $70 \mathrm{mM}$; dextrose, $100 \mathrm{mM}$; $\mathrm{pH} 4.4$ ) as an anticoagulant at a ratio of 1:5 parts ACD/blood and diluted 1:1 with HEPES-Tyrode's buffer $(137 \mathrm{mM}$ $\mathrm{NaCl}, 20 \mathrm{mM}$ HEPES, $5.6 \mathrm{mM}$ glucose, $1 \mathrm{~g} / 1 \mathrm{BSA}, 1$ $\mathrm{mM} \mathrm{MgCl}_{2}, 2.7 \mathrm{mM} \mathrm{KCl}, 3.3 \mathrm{mM} \mathrm{NaH} \mathrm{PO}_{4}$ ) before centrifugation at $100 \mathrm{~g}$ to remove red cells. Generally, blood from one mouse of a given genotype was used for Akt phosphorylation experiments, but in some cases (in particular, some of the replicate experiments of Gq knockout mice) blood from two mice of the same genotype was pooled. Platelets were then washed once in HEN buffer (10 mM HEPES, pH 6.5, 1 mM EDTA, 150 $\mathrm{mM} \mathrm{NaCl}$ ) containing $0.1 \mathrm{U} / \mathrm{ml}$ apyrase and resuspended at a concentration of $2 \times 10^{8}$ platelets $/ \mathrm{ml}$ in HEPES-Tyrode's buffer containing $0.1 \mathrm{U} / \mathrm{ml}$ apyrase. Samples were treated with LY294002 for 15 minutes in the dark at $37^{\circ} \mathrm{C}$ if indicated. Agonist was added in a $2-\mu \mathrm{l}$ volume to $100 \mu \mathrm{l}$ platelets per sample; platelets were incubated for 10 minutes and were lysed by addition of $5 \times$ Laemmli buffer containing a cocktail of protease inhibitors (Sigma-Aldrich). Lysates were resolved on $10 \%$ SDS-PAGE and immunoblotted with an Ab to Akt phosphorylated serine 473 (Cell Signaling Technology, Beverly, Massachusetts, USA) at a 1:500 dilution in 5\% milk. Experiments to detect glycogen synthase kinase-3 $\beta$ (GSK-3 $\beta$ ) phosphorylation were performed under the same conditions, but were immunoblotted with an $\mathrm{Ab}$ to phosphorylated serine 9 of GSK-3 $\beta$ (Cell Signaling Technology) at a 1:500 dilution in $5 \%$ milk.

Platelet aggregation. Blood was isolated from the inferior vena cava of anesthetized mice $(100 \mathrm{mg} / \mathrm{kg}$ pentobarbital) using a heparinized syringe $(15 \mathrm{U} / \mathrm{ml}$ blood $)$, diluted 1:1 with HEPES-Tyrode's buffer, and spun at $100 \mathrm{~g}$ for 7 minutes to remove red cells. Generally, blood from one mouse of each genotype was used for aggregation experiments, but occasionally blood from two mice of the same genotype was pooled. The final platelet count was adjusted to $2 \times 10^{8} / \mathrm{ml}$ with platelet-poor plasma from the same mouse. Aggregation was initiated with $2.5 \mu \mathrm{l}$ of agonist applied to a $250-\mu 1$ aliquot of platelet-rich plasma (PRP) and measured in a ChronoLog Corp. lumiaggregometer (Havertown, Pennsylvania, USA).

Dense-granule secretion. PRP prepared as described above was pooled from two mice of each genotype, incubated for 30 minutes at $37^{\circ} \mathrm{C}$ with $\left({ }^{3} \mathrm{H}\right) 5$ - $\mathrm{HT}$ (5-hydroxytryptamine; serotonin) $(1 \mu \mathrm{Ci} / \mathrm{ml})$, washed 


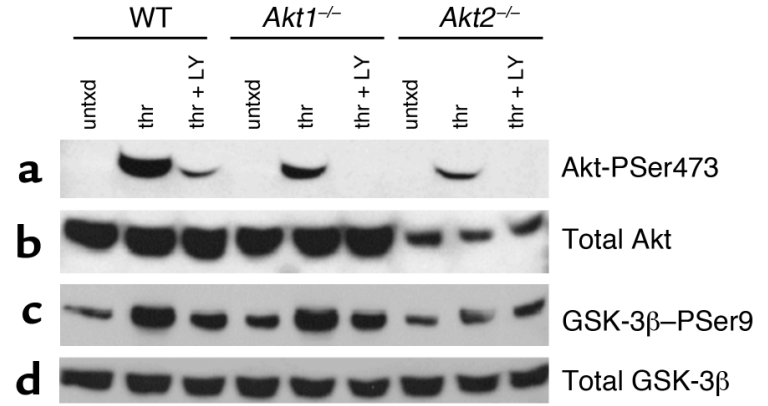

Figure 1

Phosphorylation of Akt and GSK-3 $\beta$ in WT, $A k t 1^{-/-}$, and $A k t 2^{-/-}$mice. Washed platelets $\left(2 \times 10^{7}\right.$ platelets in $\left.100 \mu \mathrm{l}\right)$ were stimulated for 10 minutes with buffer alone (untxd), thrombin (thr; $1 \mathrm{U} / \mathrm{ml}$ ), or thrombin in the presence of the PI3K inhibitor, LY294002 (thr + LY; $50 \mu \mathrm{M}$ ) and then immunoblotted with Ab's directed against (a) Akt phosphorylated on serine 473 (Akt-PSer473), (b) total Akt, (c) GSK-3 $\beta$

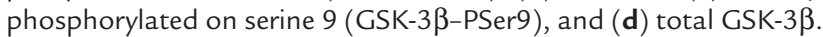
The results shown are representative of those obtained a minimum of three times.

once with HEN containing $1 \mu \mathrm{M}$ imipramine, then resuspended in HEPES-Tyrode's buffer containing 1 $\mu \mathrm{M}$ imipramine and $1 \mathrm{mM} \mathrm{CaCl}_{2}$. Platelets $\left(4 \times 10^{8} / \mathrm{ml}\right)$ were stimulated (in $200-\mu \mathrm{l}$ aliquots) with the indicated concentrations of AYPGQV for 10 minutes at $37^{\circ} \mathrm{C}$. Reactions were stopped with an equal volume of $0.1 \mathrm{M} \mathrm{EDTA} / 2 \%$ formaldehyde and centrifuged for 10 minutes at $900 \mathrm{~g}$. Percentage of 5-HT release was defined as the agonist-related increase in extracellular ${ }^{3} \mathrm{H}$ divided by the total intracellular ${ }^{3} \mathrm{H}$ at the start of the experiment.

$\alpha$-Granule secretion and fibrinogen binding. To measure platelet $\alpha$-granule secretion, washed mouse platelets $\left(10^{8} / \mathrm{ml}\right)$ were incubated simultaneously with $1 \mu \mathrm{g} / \mathrm{ml}$ FITC-labeled anti-P-selectin $\mathrm{Ab}$ (PharMingen, San Diego, California, USA) and indicated concentrations of agonist peptide AYPGQV at $37^{\circ} \mathrm{C}$ for 20 minutes, then fixed in $1 \%$ formalin containing Tyrode's buffer for 10 minutes at $37^{\circ} \mathrm{C}$, diluted five times with Tyrode's buffer, and analyzed by flow cytometry. To measure fibrinogen binding, platelets were treated as above, but incubated with FITC-labeled mouse fibrinogen (100 $\mu \mathrm{g} / \mathrm{ml}$ ) instead of P-selectin Ab.

Ferric chloride carotid artery injury model of thrombosis. The exposed carotid artery of an adult mouse (6-10 weeks of age, $18-30 \mathrm{~kg}$ ) was placed in contact with a strip of filter paper soaked with $10 \% \mathrm{FeCl}_{3}$ for 2.5 minutes before being rinsed with PBS, essentially as described (21). Blood flow in the artery was recorded for the next 30 minutes with a Doppler flow probe.

Tail-bleeding times. Tails of anesthetized mice (pentobarbital $100 \mathrm{mg} / \mathrm{kg})(6-10$ weeks of age, $18-30 \mathrm{~kg})$ were transected $1 \mathrm{~mm}$ from the tip with a scalpel, the remaining tail was immersed in $37^{\circ} \mathrm{C}$ saline, and the time until bleeding stopped for more than 1 minute was observed and recorded.

\section{Results}

Akt 1 and Akt2 are expressed in mouse platelets and activated by thrombin. It has been reported previously that human platelets express mRNA for both Akt 1 and Akt2, but not Akt3 (14). Akt1 and Akt2 are $81 \%$ identical at the amino acid level. Because Ab's raised to Akt1 versus Akt2 have not proved to be very selective, immunoblots were made with platelets from WT, $A k t 1^{-/-}$, and $A k t 2^{-/-}$ mice using an $\mathrm{Ab}$ that recognizes both isoforms, as well as with a second $\mathrm{Ab}$ that recognizes the activationdependent phosphorylation of Akt at serine 473 (serine 474 in Akt2) (22). The immunoblot in Figure 1a shows that Akt is phosphorylated at serine 473 in thrombin-treated WT platelets. It also shows that the extent of phosphorylation is slightly reduced in Akt1-/platelets and dramatically reduced in $A k t 2^{-/-}$platelets. As reported previously $(14,23)$, Akt phosphorylation is inhibited in the presence of PI3K inhibitors. Immunoblots of platelet lysates reprobed with an $\mathrm{Ab}$ that recognizes all three Akt isoforms reveal that platelets from $A k t 2^{-/-}$mice express less total Akt than either WT or $A k t 1^{-/-}$platelets (Figure $\left.1 \mathrm{~b}\right)$. Phosphorylation of endogenous GSK-3 $\beta$ was used to determine the relative amounts of Akt activity in platelets from each genotype. The experiment illustrated in Figure 1c shows that in platelets from $A k t 1^{-/-}$mice, serine 9 of GSK-3 $\beta$ is phosphorylated in response to thrombin to the same extent as in WT platelets, but that this increase in phosphorylation is reduced in Akt2-1platelets. The same results were found when platelets were stimulated with the PAR4 agonist peptide, AYPGQV (not shown). Thus, the results show that platelets express more Akt 2 than Akt 1 and that loss of Akt2 has a greater effect on phosphorylation of an Akt substrate than does loss of Akt 1 .

Platelets lacking Akt2 or multiple alleles of Akt1 and Akt2 have defects in platelet aggregation. Since it is clear that Akt is expressed in platelets and activated by platelet agonists, we next asked whether Akt plays a role in supporting platelet aggregation. To determine whether Akt1 or Akt2 is important in maintaining stable platelet aggregates, PRP was isolated from Akt-deficient mice and their WT littermates, and aggregation was observed in response to a panel of platelet agonists. Platelets from $A k t 2^{-/-}$mice showed a substantial defect in aggregation in response to low concentrations of PAR4 thrombin receptor agonist, AYPGQV $(250 \mu \mathrm{M})$, and the thromboxane A2 analogue, U46619 (1 $\mu \mathrm{M})$ (Figure 2a). Raising the agonist concentration of either agonist overcame the defect (the results with AYPGQV are shown in Figure 2b). In contrast, platelets from $A k t 1^{-/-}$mice responded normally to all concentrations of these agonists. Notably, both $A k t 1^{-/}$and $A k t 2^{-/-}$ platelets aggregated normally in response to ADP and collagen at all concentrations tested, including very low concentrations of these agonists $(0.25 \mu \mathrm{M}$ ADP and 2.5 $\mu \mathrm{g} / \mathrm{ml}$ collagen) that resulted in only $10-20 \%$ aggregation (Figure $2 \mathrm{a}$ and additional data not shown). Platelets from $A k t 1^{-/-}$mice and $A k t 2^{-/-}$mice also 
a
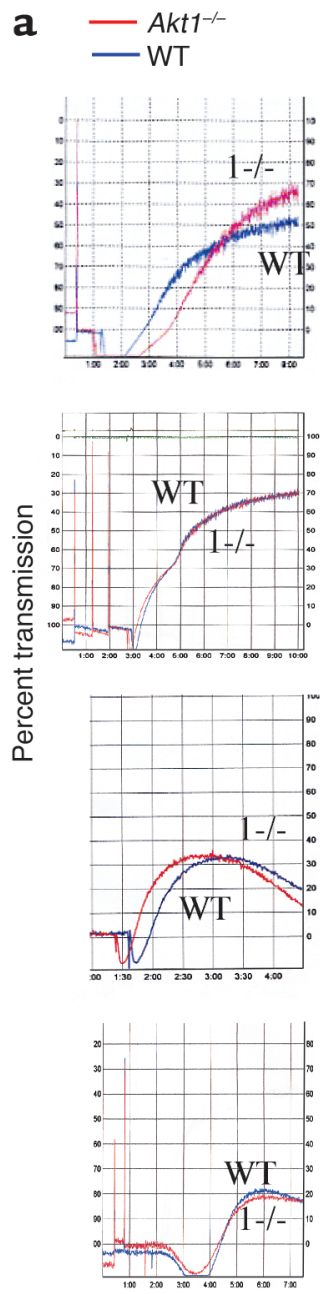

b

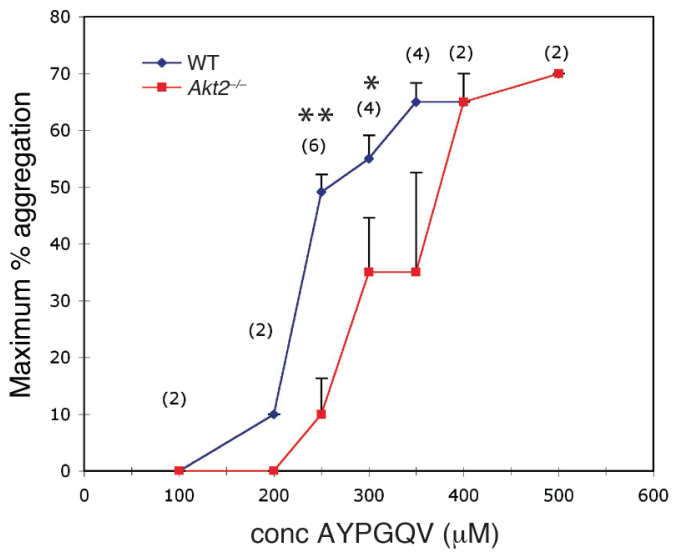

showed no defects in the ability of epinephrine to potentiate aggregation in the presence of subthreshold concentrations of ADP (data not shown). There were no apparent defects in platelet shape change in response to any agonist tested.

Mice that are null for both $A k t 1$ and Akt2 die immediately after birth (24). Therefore, to determine the extent to which each isoform may compensate for the other, aggregation was tested in platelets from
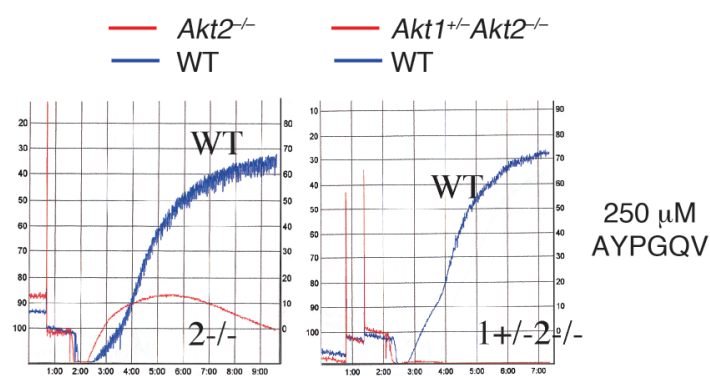

$250 \mu \mathrm{M}$
AYPGQV
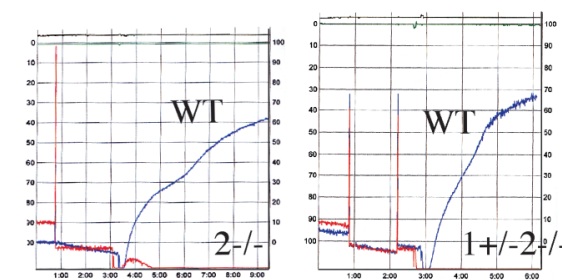

$1 \mu \mathrm{M}$ U46619
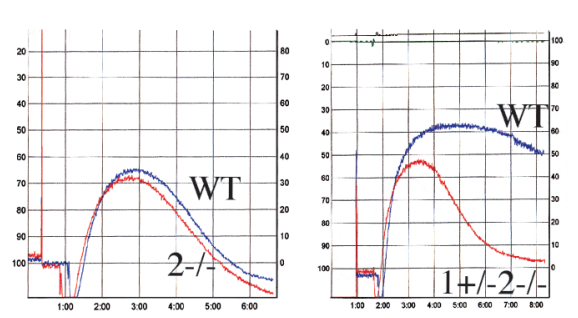

$1 \mu \mathrm{M}$

ADP
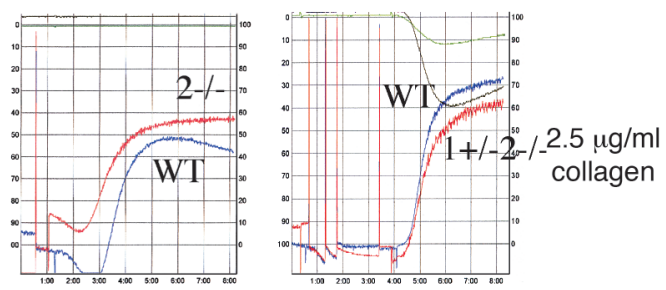

Time (min)

\begin{abstract}
Figure 2
Platelet aggregation. (a) A representative aggregation tracing is shown for each agonist and genotype tested. (b) The maximum extent of aggregation observed in response to increasing doses of AYPGQV was compared in WT versus $A k t 2^{-/-}$mice. Each point is the mean \pm SEM of two to six experiments $\left({ }^{*} P<0.05\right.$ and ${ }^{*} P<0.005$ using a paired Student's $t$ test; number of experiments $n$ is shown in parentheses above each data point). conc, concentration.
\end{abstract}

$A k t 1^{-/-} A k t 2^{+/-}$mice and $A k t 1^{+/-} A k t 2^{-/-}$mice. In contrast to $A k t 1^{-/-}$, platelets from $A k t 1^{-/-} A k t 2^{+/-}$mice had mild aggregation defects that approached those of the Akt2- $2^{--}$platelets when stimulated with low concentrations of AYPGQV and U46619. This mild defect is probably largely due to the loss of the single allele of Akt2, since $A k t 2^{+/-}$platelets have an aggregation profile very similar to that of $A k t 1^{-/-} A k t 2^{+/-}$mice (Figure 2a). $A k t 1^{+/}$platelets responded normally to all agonists test- 

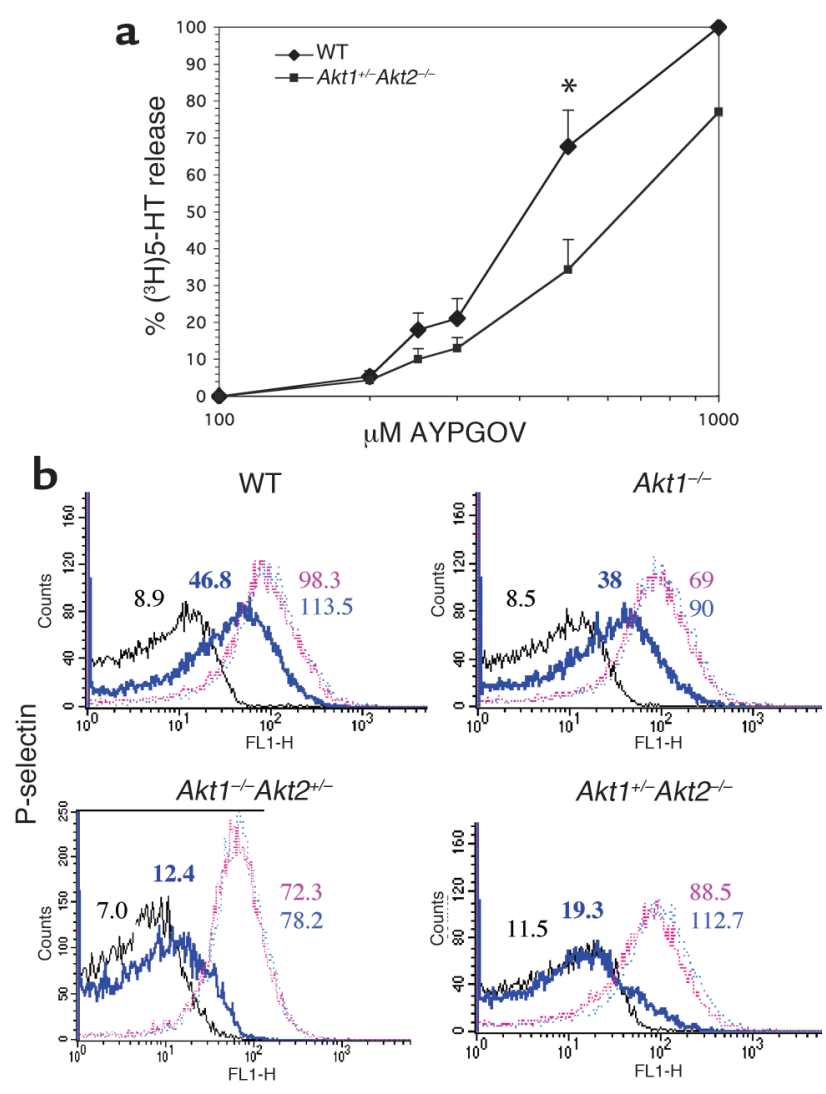

ed (data not shown). Platelets from $A k t 1^{+/-} A k t 2^{-/-}$mice displayed the most obvious defects, showing no aggregation at $250 \mu \mathrm{M}$ AYPGQV or $1 \mu \mathrm{M} \mathrm{U} 46619$, concentrations that induce $50-80 \%$ aggregation in platelets from WT control animals. Even in $A k t 1^{+/-} A k t 2^{-/-}$ platelets, however, the aggregation defect was overcome at $500 \mu \mathrm{M}$ AYPGQV and $5 \mu \mathrm{M} \mathrm{U} 46619$, at which concentrations aggregation occurred normally (not shown). Akt1 $1^{+-} A k t 2^{-1-}$ platelets also formed unstable aggregates in response to concentrations of ADP (1 $\mu \mathrm{M})$ that induced normal aggregation in their WT counterparts. Thus, the loss of Akt 2 alone causes a shift in the dose-response curve of AYPGQV (shown in Figure 2b) and U46619 required for maximal aggregation. The loss of one of the two Akt1 alleles in addition to Akt2 caused a further reduction in responses to AYPGQV and U46619 and uncovered a role for Akt in ADP-induced aggregation.

Platelets with reduced levels of Akt have defects in secretion and fibrinogen binding. When platelets are activated by thromboxane $\mathrm{A}_{2}$ or low concentrations of thrombin, secretion of ADP from platelet-dense granules is required for maximal aggregation. This is accompanied by secretion of adhesion proteins from $\alpha$-granules, which also contributes to platelet aggregation. Since loss of Akt affected platelet aggregation in response to U46619 and AYPGQV far more than did $\mathrm{ADP}$, we reasoned that Akt may be involved in platelet secretion. To study dense-granule secretion, washed platelets labeled with $\left({ }^{3} \mathrm{H}\right) 5$-HT were stimulated with

\section{Figure 3}

Secretion in WT versus Akt-deficient platelets. (a) Dense-granule secretion. Release of $\left({ }^{3} \mathrm{H}\right) 5-\mathrm{HT}$ was determined after incubation with the indicated concentrations of AYPGQV. The results shown are the mean \pm SEM of three experiments, ${ }^{*} P<0.05$ (Student's $t$ test). (b) Platelet $\alpha$-granule secretion. Washed human platelets were stimulated with buffer alone (black line), $250 \mu \mathrm{M}$ AYPGQV (bold blue line), $500 \mu \mathrm{M}$ AYPGQV (pink line), or 1M AYPGQV (light blue line), stained with FITC-labeled anti-P selectin $A b$, and analyzed by flow cytometry. Similar results were obtained in an additional two experiments. FL1-H, fluorescence intensity.

increasing concentrations of AYPGQV under nonaggregating conditions (without fibrinogen or stirring), and release of $\left({ }^{3} \mathrm{H}\right) 5$-HT was measured. Figure $3 \mathrm{a}$ shows that in platelets from $A k t 1^{+-} A k t 2^{-/-}$mice, AYPGQV-stimulated $\left({ }^{3} \mathrm{H}\right) 5-\mathrm{HT}$ release was reduced nearly $50 \%$ compared with WT platelets at concentrations up to $500 \mu \mathrm{M}$. These differences, however, were reduced at higher agonist concentrations.

To determine whether Akt-deficient platelets also exhibited defects in $\alpha$-granule secretion, platelets were stimulated with increasing concentrations of AYPGQV, and the binding of a FITC-conjugated $\mathrm{Ab}$ that recognizes the $\alpha$-granule protein, P-selectin, was monitored by flow cytometry. A shift in the dose-response curve relative to WT platelets was seen in platelets from $A k t 1^{+/-} A k t 2^{-1-}$ and, to a lesser extent, $A k t 1^{-1-} A k t 2^{+/-}$mice. This difference was most evident when responses to $250 \mu \mathrm{M}$ AYPGQV were compared (Figure 3b). The responses of $A k t 2^{-/-}$platelets looked like those of $A k t 1^{+/-} A k t 2^{-/-}$(not shown). P-selectin binding to $A k t 1^{-/-}$ platelets is similar to WT at all agonist concentrations tested. Therefore, platelet $\alpha$-granule and dense-granule secretion are significantly impaired in platelets lacking Akt2, but not in platelets lacking Akt 1 alone.
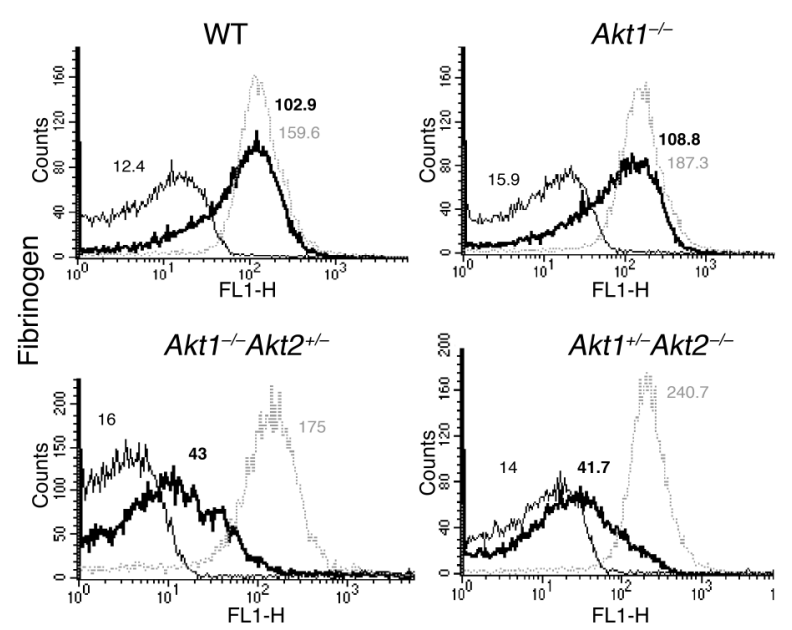

Figure 4

Fibrinogen binding in WT versus Akt-deficient platelets. Washed human platelets were treated with buffer alone (thin black line), $250 \mu \mathrm{M}$ AYPGQV (heavy black line), or $500 \mu \mathrm{M}$ AYPGQV (light gray line) as described in Figure $3 \mathrm{~b}$ but stained with FITC-labeled mouse fibrinogen $(100 \mu \mathrm{g} / \mathrm{ml})$. The results shown are representative of three experiments. 

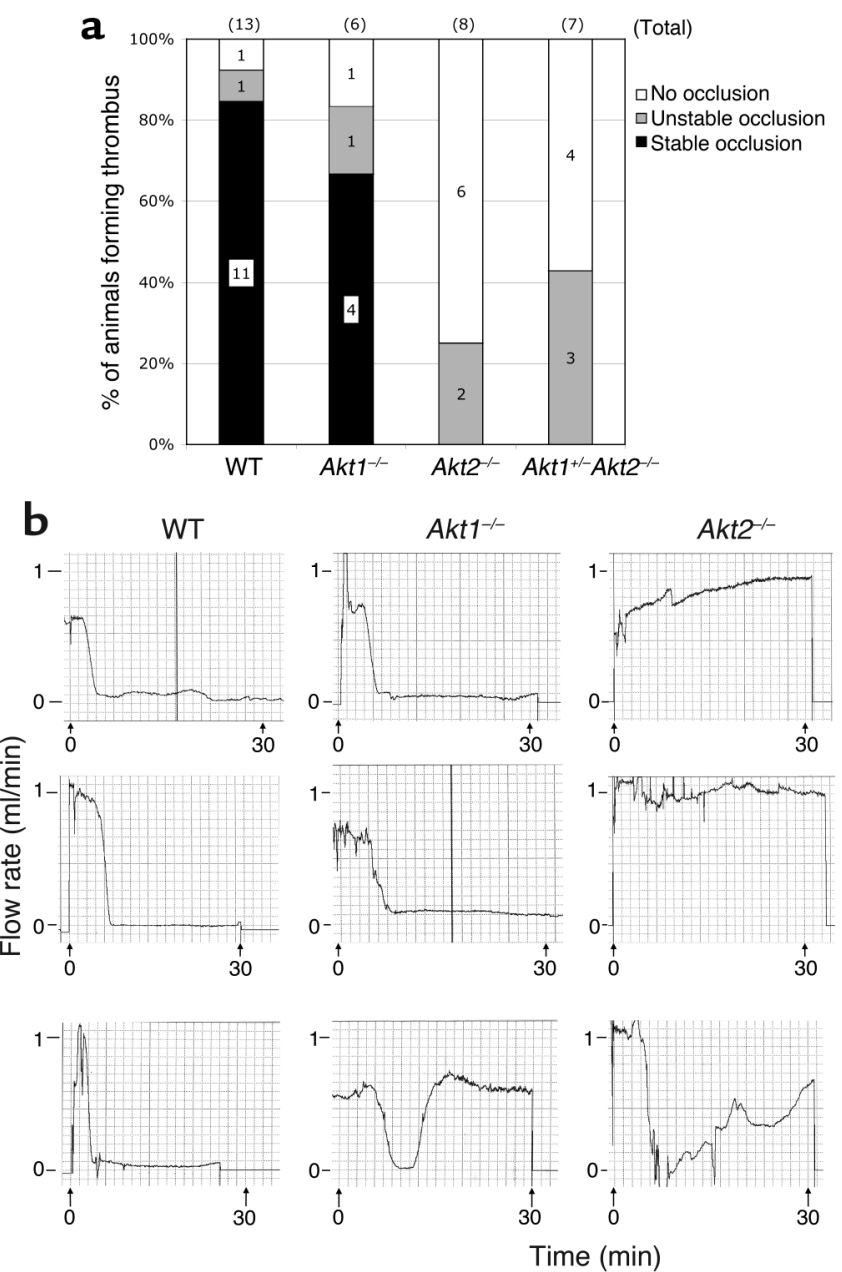
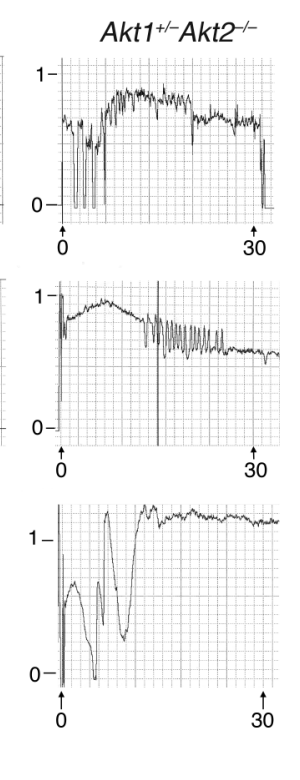

\section{Figure 5}

Thrombotic response of mice to ferric chloride injury of the carotid artery. Flow rates were measured in the carotid artery following exposure to $\mathrm{FeCl}_{3}$. (a) For each genotype, the number of mice forming a stable occlusion (flow rate $=0.1 \mathrm{ml} / \mathrm{min}$ ) that did not dislodge during the 30-minute time interval are shown in black. The number of mice that formed a transient occlusion that resolved (rate $=0.2 \mathrm{ml} / \mathrm{min}$ ) is shown in gray, and the number of mice whose arteries remained patent throughout the period of observation is shown in white. (b) Representative flow traces for each genotype.
To determine whether deficiencies in Akt signaling might contribute to differences in fibrinogen binding, the binding of FITC-labeled fibrinogen to the surface of WT versus Akt-deficient platelets was tested. Stimulation with $250 \mu \mathrm{M}$ AYPGQV induced less fibrinogenbinding to platelets from $A k t 1^{+/-} A k t 2^{--}, A k t 2^{-/-}$(equivalent to $A k t 1^{+/-} A k t 2^{-/-}$mice; not shown), and $A k t 1^{-1-} A k t 2^{+/-}$mice than to WT or $A k t 1^{-/}$platelets (Figure 4). As with P-selectin expression, this difference was overcome at higher agonist concentrations, indicating that reducing the amount of platelet Akt2 expression shifts the dose-response curve for both P-selectin expression and fibrinogen binding to the right.

Mice lacking Akt2 are resistant to thrombosis after $\mathrm{FeCl}_{3}$ injury of the carotid artery, but have normal tail-bleeding times. To determine whether the defects in platelet function observed in vitro might affect thrombus formation in vivo, we compared responses of WT mice to those lacking one or more isoform of Akt in a carotid artery injury model. In these experiments, a filter paper soaked in $10 \%$ ferric chloride was applied to the surface of the carotid artery of the mice for 2 minutes, $30 \mathrm{sec}-$ onds, after which the flow rate through the artery was recorded for 30 minutes with a Doppler flow probe. A histogram of the accumulated results is shown in Fig- ure 5, along with representative flow traces of each genotype tested. In each of the animals tested, the flow rate before application of $\mathrm{FeCl}_{3}$ was $0.8-1.1 \mathrm{ml} / \mathrm{min}$. After the injury, a reduction in flow rate that remained at $0-0.1 \mathrm{ml} / \mathrm{min}$ until the assay was terminated at 30 minutes was scored as a stable occlusive thrombus. Animals in which blood flow stopped, but then resumed, were scored as having an unstable thrombus. Male and female mice of each genotype were tested, but no differences in results due to mouse gender were observed. In WT and $A k t 1^{-1-}$ mice, stable occlusive thrombi formed in $85 \%$ and $67 \%$ of the mice tested, respectively. In contrast, none of the $A k t 2^{-/-}$mice or $A k t 1^{+/-} A k t 2^{-/-}$ mice formed a stable thrombus in response to injury. In fact, the majority of the Akt2 $2^{-/-}$mice and $A k t 1^{+-} A k t 2^{-/-}$ mice never formed a thrombus in response to injury, whereas only $8 \%$ of WT and $17 \%$ of $A k t 1^{-1-}$ mice failed to form a thrombus. Unstable thrombi were also seen in a greater proportion of $A k t 2^{-/-}$and $A k t 1^{+/-} A k t 2^{-/-}$ mice than WT or $A k t 1^{-/-}$mice. Thus, mice lacking Akt2 are resistant to thrombosis after ferric chloride injury to the carotid artery. In contrast, tail bleeding times in $A k t 1^{-/}, A k t 2^{---}$, and $A k t 1^{+--} A k t 2^{-/-}$mice were normal relative to WT mice (Figure 6). These data suggest that Akt (Akt2 in particular) is critical for stabilizing thrombus 


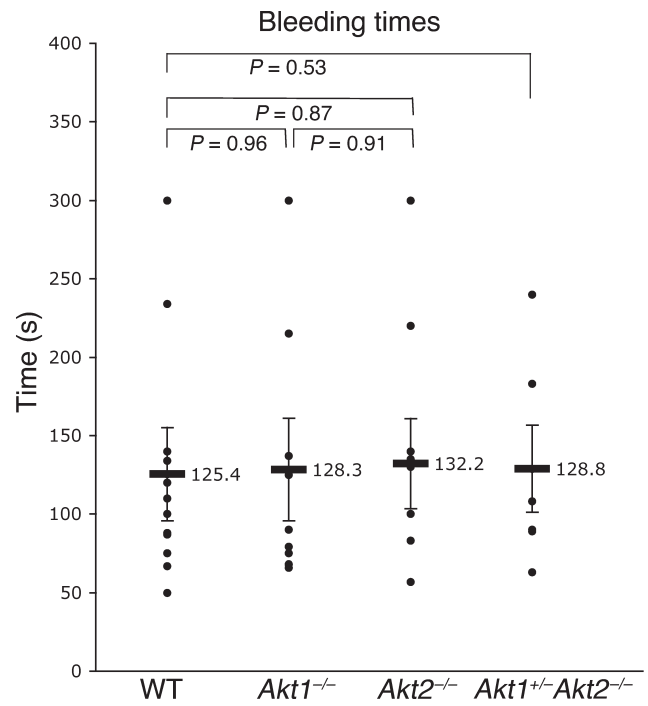

Figure 6

Tail bleeding times for WT, $A k t 1^{-1-}$, and $A k t 2^{-/-}$mice. Bleeding times were performed as described in Methods. The mean \pm SD for each genotype is indicated.

formation after arterial injury, but is not required for hemostatic plug formation after transection of the veins and arterioles in the tail. The difference in the role of Akt in these two models of in vivo platelet plug formation may reflect differences in Akt activation under the divergent flow rates encountered in the carotid artery versus the tail veins.

Akt is phosphorylated in a $G_{i 2}$-dependent manner by $A D P$ and in $a G_{q}$-dependent fashion by thrombin. Our data, along with those published previously, show that phosphorylation of Akt is detected after platelets are stimulated with thrombin, ADP, or U46619 and that Akt is phosphorylated in a PI3K-dependent fashion. Because platelets treated with PI3K inhibitors fail to form stable aggregates, as do platelets treated with scavengers of ADP (1), it is tempting to speculate that the role of Akt in stabilizing platelet aggregates is either mediated by release of ADP or is a consequence of ADP release. In other words, either activation of Akt enhances release of $\mathrm{ADP}$, thereby stabilizing platelet aggregates, or release of ADP is first required for Akt activation. Our results suggest that the former, rather than the latter, is the case, since deletion of Akt2 reduces responses to PAR4 agonist more than responses to ADP. Nevertheless, to more easily distinguish between these possibilities, phosphorylation of Akt by thrombin and ADP was tested in platelets lacking $G \alpha_{q}$ or $G \alpha_{i 2}$. The results are shown in Figure 7. The dominant thrombin receptor on mouse platelets, PAR4, couples directly to $G_{q}$, but activates $G_{i}$ by way of secreted ADP (2). ADP binds to two receptors on platelets: P2Y1, coupled to $G_{q}(19)$, and P2Y12, coupled to $\mathrm{G}_{\mathrm{i} 2}$ (4). As previously reported, incubating WT platelets with ADP (15) or thrombin (14) resulted in Akt phosphorylation. Loss of $G_{q}$ abolished Akt phosphorylation in response to thrombin, but had little effect on phosphorylation in response to ADP. Conversely, loss of $G_{i 2}$ abolished Akt phosphorylation by ADP, but only marginally reduced Akt phosphorylation by thrombin (a small reduction is evident at very low exposures). These results suggest that there are both $\mathrm{G}_{\mathrm{q}}$ - and $\mathrm{G}_{\mathrm{i}}$-dependent pathways that are capable of activating Akt independently. The results also show that thrombin can stimulate Akt phosphorylation independently of ADP secretion. Taken together with our data showing that removal of platelet Akt impairs secretion, these results suggest that the role of Akt in stabilizing platelet aggregates is at least partially due to a role in enhancing release of $\mathrm{ADP}$, rather than due to a requirement of $\mathrm{ADP}$ secretion for activation of Akt.

\section{Discussion}

It has been recognized for some time that PI3Ks play a role in promoting and maintaining platelet aggregation. The molecular targets of the products of PI3K in platelets and their respective functions have not been completely defined, however. One target of PI3K products in many cells, including platelets, is the serine/threonine kinase Akt (25). Akt has been implicated in a diverse array of functions in different cells, including suppression of apoptosis, glucose metabolism, and cell proliferation (16). It appears from heterologous expression studies and the phenotypes of the individual knockouts that the three known isoforms of Akt (Akt1, 2, and 3) serve distinct, but overlapping, functions. Akt1 is ubiquitously expressed, and $A k t 1^{-/-}$mice have a general defect in organismal growth but little or no defect in glucose metabolism (17). Akt2 is highly expressed in pancreatic $\beta$ cells, skeletal muscle, and brown fat (26, 27). Akt2 $2^{--}$mice produced by two different groups are hyperglycemic, hyperinsulinemic, and have defects in insulin responses $(18,28)$. Those produced by Cho et al. exhibit a compensatory increase in pancreatic $\beta$ cell mass, while those studied by Garofalo et al. display an age-dependent loss of adipose tissue, and some $A k t 2^{-/-}$ males develop more severe hyperglycemia due to $\beta$ cell failure. The differences in phenotype observed between

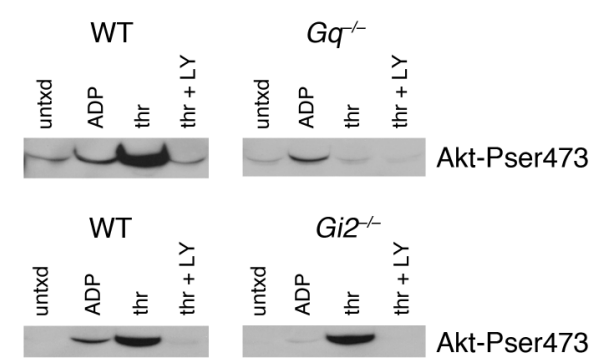

\section{Figure 7}

Akt phosphorylation in platelets from $\mathrm{Gq}^{-/-}$and $\mathrm{Gi}^{-/-}$mice. Washed platelets were obtained and incubated with buffer alone, ADP (10 $\mu \mathrm{M})$, thrombin $(1 \mathrm{U} / \mathrm{ml})$, or thrombin + LY294002 (50 $\mu \mathrm{M})$ using the protocol described in Figure 1, then immunoblotted with an $A b$ specific for phosphorylated Akt serine 473. The results shown are representative of those obtained four times each. 


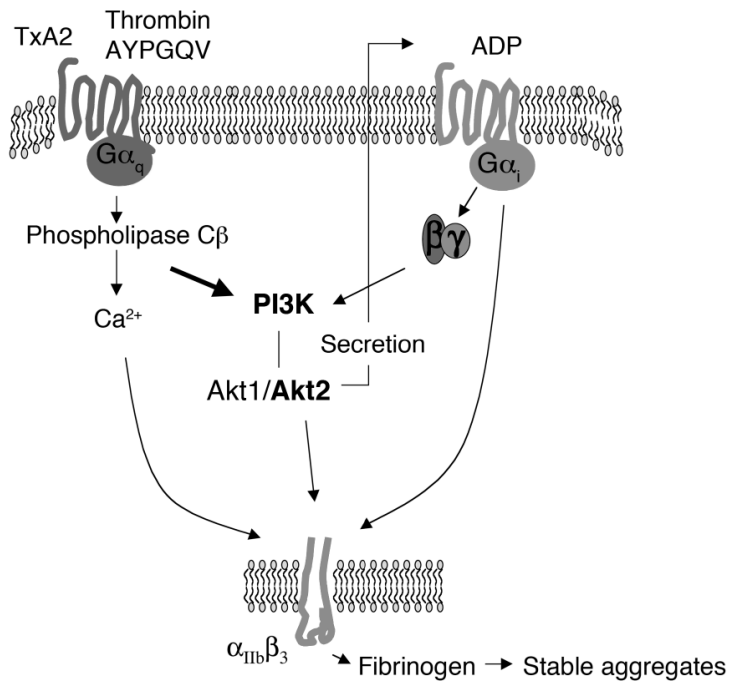

Figure 8

Role of Akt in platelet aggregation. Akt is activated in a PI3K-dependent fashion by thromboxane A2 (TxA2) or thrombin. Akt activation promotes secretion of ADP from platelet-dense granules, which stimulates $\mathrm{G}_{\mathrm{i}}$-coupled pathways by binding to the $\mathrm{P} 2 \mathrm{Y} 12$ receptor, thereby enhancing aggregate formation and stability.

these two groups is probably attributable to modifier genes present to varying extents in the $129 / \mathrm{C} 57 \mathrm{BL} / 6$ background of $A k t 2^{-1-}$ mice from Cho et al. versus the inbred DBA/1lacJ background of $A k t 2^{-/-}$mice from

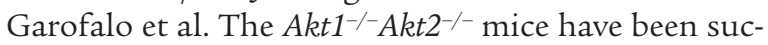
cessfully generated by one group, but die immediately after birth with documented defects in bone development, adipogenesis, and growth (24). Akt3 is expressed predominantly in the brain and testes and is upregulated in some cancer cells (29). The effects of genetic deletion of $A k t 3$ are yet to be reported.

The mRNA for Akt 1 and Akt2, but not Akt3, has been detected in human platelets (14). We show here that mouse platelets express both Akt1 and Akt2 at the protein level, leading us to ask the following questions: What is the role of Akt in platelet signaling and aggregation? Do Akt 1 and Akt 2 have distinct roles? Is the role of Akt in platelet function important for thrombus formation in vivo? To answer these questions, we have examined platelet function in mice with reduced expression of Akt1, Akt2, or a combination of both. We have also evaluated the role of Akt in the ferric chloride injury model of arterial thrombosis. The results show a definitive role for Akt in stabilizing platelet aggregation in vitro and in platelet plug formation in vivo.

To better understand how Akt becomes activated in platelets, agonist-mediated Akt phosphorylation was evaluated. Although thrombin, collagen, and thromboxane $\mathrm{A}_{2}$ clearly stimulate Akt phosphorylation in platelets $(5,14,30,31)$, there are conflicting data on whether ADP is capable of doing so. The frequent failure to detect ADP-mediated Akt phosphorylation is likely due to the rapid desensitization of the $\mathrm{G}_{\mathrm{q}}$-coupled ADP receptor, P2Y1 (32). This was avoided by iso- lating platelets in the presence of ADP scavengers, in which case Akt phosphorylation was evident, although less robust than that caused by thrombin. A second receptor for ADP on platelets, P2Y12, is coupled primarily to the $\mathrm{G}_{\mathrm{i}}$ family member, $\mathrm{G}_{\mathrm{i} 2}(4,33)$. Studies showing that platelets lacking $\mathrm{G}_{\mathrm{i} 2}$ or the $\mathrm{P} 2 \mathrm{Y} 12$ receptor have reduced responses to thrombin $(2,4,34)$ and that blockade of P2Y12 destabilized platelet aggregates (35) raised the possibility that thrombin-mediated Akt phosphorylation might be mediated by ADP release. Our studies of Akt phosphorylation in $\mathrm{G \alpha}_{\mathrm{i} 2}$ - versus $\mathrm{G} \alpha_{\mathrm{q}}$-null platelets showed that thrombin can stimulate Akt phosphorylation under conditions where ADP cannot, suggesting that platelets stimulated with thrombin (or U46619) do not require secreted ADP to activate Akt, although ADP can amplify Akt activation by stimulating $\mathrm{G}_{\mathrm{i} 2}$-coupled $\mathrm{P} 2 \mathrm{Y} 12$ receptors. This conclusion is consistent with two previous studies: (a) Hirsch et al. found that Akt phosphorylation by ADP in platelets is at least partially dependent on PI $3 \mathrm{~K} \gamma$, while thrombin-mediated Akt phosphorylation is largely normal in the absence of PI3K $\gamma$ (15); and (b) Li et al. recently showed that U46619-mediated phosphorylation of Akt is only partially inhibited by antagonists of P2Y12 (5).

What, then, is the role of Akt in platelets? The agonist-selective nature of the aggregation defects in platelets lacking alleles of Akt 2 would suggest that Akt is more important for promoting responses to low concentrations of agonists that stimulate $\mathrm{G}_{\mathrm{q}}$-coupled receptors (such as the thromboxane prostanoid [TP] receptor for thromboxane $\mathrm{A}_{2}$ and PAR4 thrombin receptor) than those coupled to $\mathrm{G}_{\mathrm{i}}$ (such as the P2Y12 or $\alpha_{2 \mathrm{a}}$ adrenergic receptors). Because platelets stimulated with low concentrations of U46619 or AYPGQV require secretion of ADP to achieve maximum aggregation $(2,36)$, we suspected that a defect in secretion may underlie the aggregation defect. Our data showing that platelets from mice that lack Akt2 alleles exhibit impaired secretion from both dense and $\alpha$-granules and have a parallel reduction in fibrinogen binding relative to their WT counterparts confirm that this may be the case. It is notable that the secretion measurements were done under nonaggregating conditions, that is, in the absence of fibrinogen and stirring. Thus, it appears that Akt-deficient platelets have a defect in secretion that results in reduced fibrinogen binding and, consequently, impaired aggregation.

It is interesting and unexpected that collagen-mediated aggregation was not noticeably impaired in the Akt-deficient mice. Collagen-induced Akt phosphorylation has been detected under nonaggregating conditions, although its phosphorylation is delayed (up to 5 minutes) relative to thrombin (31). It is possible that Akt activation by collagen does not take effect quickly enough to contribute to aggregation. Other possibilities are that loss of Akt 2 is more easily compensated by Akt 1 when platelets are activated by collagen than other agonists or that collagen signaling requires high 
shear rates to sustain Akt activation. It is interesting that mice lacking the $\mathrm{p} 85 \alpha$ subunit of PI3K have a defect in collagen-mediated platelet aggregation, but no defect in bleeding time, perhaps indicating that defects in collagen signaling require conditions of higher shear to affect platelet plug formation in vivo (37). Mice lacking PI3K $\gamma$ also have normal tail bleeding times but are resistant to ADP-induced thromboembolism (15). We show here that mice lacking Akt2, a known effector of PI3K, have an impaired ability to form thrombi following arterial injury, but, like mice deficient in PI3K isoforms, have normal bleeding times. It is tempting to speculate that the loss of $A k t 2$ expression has a greater effect on thrombus formation in the carotid because of the higher flow rates that are present in that relatively large artery compared with the small arteries and veins in the distal $1 \mathrm{~mm}$ of the tail. Although PI3K may regulate pathways other than those downstream of Akt, our studies, as well as others $(14,23)$, show that thrombin-stimulated Akt phosphorylation is predominantly PI3K dependent. Mouse platelets treated with PI3K inhibitors, such as $A k t 1^{+/-} A k t 2^{-/-}$platelets, are unresponsive to low concentrations of AYPGQV or U46619, indicating that removal of Akt reproduces the effects of PI3K inhibitors on aggregation. Defects in platelet function may be more severe in platelets that completely lack both Akt1 and Akt2. It appears that Akt3 is not expressed in mouse platelets, since immunoblots with an $\mathrm{Ab}$ selective for Akt3 were negative (not shown). Defects in platelet function were clearly more apparent in $A k t 2^{-/-}$than $A k t 1^{-/-}$platelets, demonstrating that Akt2 plays a more important role in platelets than Akt1. This seems a simple reflection of the relative expression levels of the two isoforms, since immunoreactivity of a nonsubtype selective Akt Ab and phosphorylation of the Akt substrate GSK-3 $\beta$ were clearly reduced in $A k t 2^{-/-}$platelets relative to both $A k t 1^{-/-}$and WT platelets. Because loss of a single Akt2 allele also results in mild defects in platelet aggregation, but $A k t 2^{+/-}$mice are metabolically normal, the platelet function defect does not appear to be due to changes in plasma glucose or insulin concentrations.

Returning to the role of Akt in platelet function in vivo, the effect of loss of Akt 2 on thrombus formation in vivo is particularly interesting given that the platelet function defects observed in vitro were agonist selective and overcome at higher agonist concentrations. Although it is possible that reduced expression of Akt2 by other cells in the vasculature may contribute to the observed effects of Akt 2 deletion on thrombosis in vivo, the effects correlate nicely with the observed platelet phenotype ex vivo. Attempts to transplant Akt2-/blood into lethally irradiated WT recipients (and vice versa) are underway to determine the contribution of components of blood versus the vascular bed to the reduced thrombosis seen in Akt2-/- mice. The ferric chloride thrombosis model involves a substantial transmural insult and potentially indicates that even relatively small defects in platelet function ex vivo (such as those that shift the dose-response curve for agonist activation) can translate into important defects in thrombus formation in vivo. This observation has implications as investigators try to identify new molecular targets for drug development to treat thrombosis. That is, molecular targets that amplify or sustain platelet responses to agonist may make particularly good candidates for development of novel therapeutics.

How do we view the role of Akt in platelet function? Akt seems particularly important for supporting platelet responses to low concentrations of agonists that require secretion to amplify aggregation, such as agonists that bind to the PAR4 thrombin receptor or TP receptor for thromboxane A2. This observation is in line with the secretion defect observed in $A k t 2^{-/-}$and $A k t 1^{+/-} A k t 2^{-/-}$platelets. Akt appears to be activated by a $\mathrm{G}_{\mathrm{q}}$ - and PI3K-dependent mechanism and plays a role in secretion of ADP. ADP subsequently stimulates $\mathrm{G}_{\mathrm{i}^{-}}$ mediated pathways, which enhance the activation of $\alpha_{\text {IIb }} \beta_{3}$, promote fibrinogen binding, and increase aggregation (Figure 8).

\section{Acknowledgments}

Many thanks to Charles Abrams for helpful discussions and Donald Eslin for help in establishing the carotid artery injury model in our lab. Parts of this work were supported by grants $0365530 \mathrm{U}$ from the American Heart Association (to D. Woulfe) and NIH HL-40387 and NIH HL-45181 (to L.F. Brass).

1. Trumel, C., et al. 1999. A key role of adenosine diphosphate in the irreversible platelet aggregation induced by the PAR1-activating peptide through the late activation of phosphoinositide 3-kinase. Blood. 94:4156-4165.

2. Kim, S., et al. 2002. Protease-activated receptors 1 and 4 do not stimulate G(i) signaling pathways in the absence of secreted ADP and cause human platelet aggregation independently of G(i) signaling. Blood. 99:3629-3636.

3. Dangelmaier, C., Jin, J., Smith, J.B., and Kunapuli, S.P. 2001. Potentiation of thromboxane A2-induced platelet secretion by Gi signaling through the phosphoinositide-3 kinase pathway. Thromb. Haemost. 85:341-348.

4. Jantzen, H.-M., Milstone, D.S., Gousset, L., Conley, P.B., and Mortensen, R.M. 2001. Impaired activation of murine platelets lacking $\mathrm{G}$ alpha(i2). J. Clin. Invest. 108:477-483. doi:10.1172/JCI200112818.

5. Li, Z., et al. 2003. Two waves of platelet secretion induced by thromboxane $\mathrm{A} 2$ receptor and a critical role for phosphoinositide 3-kinases. J. Biol. Chem. 278:30725-30731.

6. Kovacsovics, T.J., et al. 1995. Phosphoinositide 3-kinase inhibition spares actin assembly in activating platelets but reverses platelet aggregation. J. Biol. Chem. 270:11358-11366.

7. Kucera, G.L., and Rittenhouse, S.E. 1990. Human platelets form 3-phosphorylated phosphoinositides in response to $\alpha$-thrombin, $\mathrm{U} 46619$, or GTP gamma S. J. Biol. Chem. 265:5345-5348.

8. Zhang, J., Shattil, S.J., Cunningham, M.C., and Rittenhouse, S.E. 1996 Phosphoinositide 3-kinase gamma and $\mathrm{p} 85$ / phosphoinositide 3-kinase in platelets. Relative activation by thrombin receptor or beta-phorbol myristate acetate and roles in promoting the ligand-binding function of

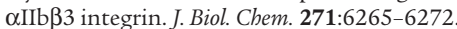

9. Sultan, C., et al. 1991 . Involvement of platelet glycoprotein IIb-IIIa ( $\alpha$ IIb- $\beta 3$ integrin) in thrombin-induced synthesis of phosphatidylinositol 3',4'-bisphosphate. J. Biol. Chem. 266:23554-23557.

10. Sorisky, A., King, W.G., and Rittenhouse, S.E. 1992. Accumulation of PtdIns $(3,4) \mathrm{P} 2$ and PtdIns $(3,4,5) \mathrm{P} 3$ in thrombin-stimulated platelets. Different sensitivities to $\mathrm{Ca} 2+$ or functional integrin. Biochem. J. 286:581-584.

11. Banfic, H., et al. 1998. A novel integrin-activated pathway forms PKB/Akt-stimulatory phosphatidylinositol 3,4-bisphosphate via phosphatidylinositol 3-phosphate in platelets. J. Biol. Chem. 273:13-16. 
12. Cantley, L.C. 2002. The phosphoinositide 3-kinase pathway. Science. 296:1655-1657.

13. Brazil, D.P., Park, J., and Hemmings, B.A. 2002. PKB binding proteins Getting in on the Akt. Cell. 111:293-303.

14. Kroner, C., Eybrechts, K., and Akkerman, J.W. 2000. Dual regulation of platelet protein kinase B. J. Biol. Chem. 275:27790-27798.

15. Hirsch, E., et al. 2001. Resistance to thromboembolism in PI3K $\gamma$-deficient mice. FASEB J. 15:2019-2021.

16. Lawlor, MA. 2001. PKB/Akt: a key mediator of cell proliferation, survival and insulin responses? J. Cell Sci. 114:2903-2910.

17. Cho, H., Thorvaldsen, J.L., Chu, Q., Feng, F., and Birnbaum, M.J. 2001 Akt1/PKBalpha is required for normal growth but dispensable for maintenance of glucose homeostasis in mice. J. Biol. Chem. 276:38349-38352.

18. Cho, H., et al. 2001. Insulin resistance and a diabetes mellitus-like syndrome in mice lacking the protein kinase Akt2 (PKB beta). Science. 292:1728-1731.

19. Offermanns, S., Toombs, C.F., Hu, Y.H., and Simon, M.I. 1997. Defective platelet activation in $\mathrm{G} \alpha(\mathrm{q})$-deficient mice. Nature. 389:183-186.

20. Woulfe, D., Jiang, H., Mortensen, R., Yang, J., and Brass, L.F. 2002. Activation of Rap1B by G(i) family members in platelets. J. Biol. Chem. 277:23382-23390

21. Kufrin, D., et al. 2003. Antithrombotic thrombocytes: ectopic expression of urokinase-type plasminogen activator in platelets. Blood. 102:926-933.

22. Bellacosa, A., et al. 1998. Akt activation by growth factors is a multiplestep process: the role of the PH domain. Oncogene. 17:313-325.

23. Lova, P., et al. 2003. A selective role for phosphatidylinositol 3,4,5trisphosphate in the Gi-dependent activation of platelet Rap1B. J. Biol. Chem. 278:131-138.

24. Peng, X.D., et al. 2003. Dwarfism, impaired skin development, skeletal muscle atrophy, delayed bone development, and impeded adipogenesis in mice lacking Akt1 and Akt2. Genes Dev. 17:1352-1365.

25. Vivanco, I., and Sawyers, C.L. 2002. The phosphatidylinositol 3-kinase AKT pathway in human cancer. Nat. Rev. Cancer. 2:489-501.

26. Altomare, D.A., Lyons, G.E., Mitsuuchi, Y., Cheng, J.Q., and Testa, J.R 1998. Akt2 mRNA is highly expressed in embryonic brown fat and the
AKT2 kinase is activated by insulin. Oncogene. 16:2407-2411.

27. Altomare, D.A., et al. 1995. Cloning, chromosomal localization and expression analysis of the mouse Akt2 oncogene. Oncogene. 11:1055-1060.

28. Garofalo, R.S., et al. 2003. Severe diabetes, age-dependent loss of adipose tissue, and mild growth deficiency in mice lacking Akt2/PKBß. J. Clin. Invest. 112:197-208. doi:10.1172/JCI200316885.

29. Nakatani, K., et al. 1999. Up-regulation of Akt3 in estrogen receptor-deficient breast cancers and androgen-independent prostate cancer lines. J. Biol. Chem. 274:21528-21532.

30. Banfic, H., Downes, C.P., and Rittenhouse, S.E. 1998. Biphasic activation of PKBalpha/Akt in platelets. Evidence for stimulation both by phosphatidylinositol 3,4-bisphosphate, produced via a novel pathway, and by phosphatidylinositol 3,4,5-trisphosphate. J. Biol. Chem. 273:11630-11637.

31. Barry, F.A., and Gibbins, J.M. 2002. Protein kinase B is regulated in platelets by the collagen receptor glycoprotein VI. J. Biol. Chem. 277:12874-12878.

32. Baurand, A., et al. 2000. Desensitization of the platelet aggregation response to ADP: differential down-regulation of the P2Y1 and P2cyc receptors. Thromb. Haemost. 84:484-491.

33. Hollopeter, G., et al. 2001. Identification of the platelet ADP receptor targeted by antithrombotic drugs. Nature. 409:202-207.

34. Andre, P., et al. 2003. P2Y12 regulates platelet adhesion/activation, thrombus growth, and thrombus stability in injured arteries. J. Clin. Invest. 112:398-406. doi:10.1172/JCI200317864.

35. Storey, R.F., et al. 2000. The central role of the $\mathrm{P}(2 \mathrm{~T})$ receptor in amplification of human platelet activation, aggregation, secretion and procoagulant activity. Br. J. Haematol. 110:925-934.

36. Paul, B.Z., Jin, J., and Kunapuli, S.P. 1999. Molecular mechanism of thromboxane A(2)-induced platelet aggregation. Essential role for p2t(ac) and alpha(2a) receptors. J. Biol. Chem. 274:29108-29114.

37. Watanabe, N., et al. 2003. Functional phenotype of phosphoinositide 3-kinase p $85 \alpha$-null platelets characterized by an impaired response to GP VI stimulation. Blood. 102:541-548. 